\title{
Progress in the Characterization of the Surface Species in Activated Carbons by means of INS Spectroscopy Coupled with Detailed DFT Calculations
}

\author{
Andrea Piovano, ${ }^{1}$ Andrea Lazzarini, ${ }^{2}$ Riccardo Pellegrini, ${ }^{3}$ \\ Giuseppe Leofanti, ${ }^{4}$ Giovanni Agostini, ${ }^{5}$ Svemir Rudić, ${ }^{6}$ Aram L. Bugaev, ${ }^{2,7}$ \\ Carlo Lamberti, ${ }^{2,7}$ and Elena Groppo ${ }^{2}$ \\ ${ }^{1}$ Institut Laue-Langevin (ILL), 71 avenue des Martyrs, 38000 Grenoble, France \\ ${ }^{2}$ Department of Chemistry, NIS Center and INSTM, University of Turin, Via Quarello 15, 10135 Turin, Italy \\ ${ }^{3}$ Chimet SpA-Catalyst Division, Via di Pescaiola 74, Viciomaggio, 52041 Arezzo, Italy \\ ${ }^{4}$ Via Firenze 43, Canegrate, 20010 Milano, Italy \\ ${ }^{5}$ European Synchrotron Radiation Facility (ESRF), 71 avenue des Martyrs, 38000 Grenoble, France \\ ${ }^{6}$ ISIS Facility, Rutherford Appleton Laboratory, Chilton, Didcot, Oxfordshire OX11 0QX, UK \\ ${ }^{7}$ Southern Federal University, Zorge Street 5, Rostov-on-Don 344090, Russia \\ Correspondence should be addressed to Andrea Lazzarini; andrea.lazzarini@unito.it
}

Received 7 May 2015; Accepted 10 August 2015

Academic Editor: Victor V. Moshchalkov

Copyright (c) 2015 Andrea Piovano et al. This is an open access article distributed under the Creative Commons Attribution License, which permits unrestricted use, distribution, and reproduction in any medium, provided the original work is properly cited.

\begin{abstract}
Activated carbons are materials with relevance in different industrial applications. Due to the inherent complexity and heterogeneity of their structures, an easy assignment of the species present on their surface has a challenging result. Only recently, with the possibility to collect well-resolved inelastic neutron spectra and to simulate by DFT methods more or less extended graphitic clusters, this task is starting to become feasible. Here we report our investigation on a steam activated carbon and we show that different vibrations in the region of out-of-plane $\mathrm{C}$ - $\mathrm{H}$ bending modes are specifically connected to hydrogen terminations belonging to extended and regular borders or to short and defective ones. Furthermore, simulations including heteroatoms such as oxygen allowed us to point out spectral regions with a contribution from carboxyl species.
\end{abstract}

\section{Introduction}

Various grades of carbon such as activated carbons or carbon blacks are used as support materials for electrocatalysts for proton exchange membrane fuel cells [1-4] and for many kinds of heterogeneous catalysts, especially precious metal type catalysts [5-8]. For instance, $\mathrm{Pd} / \mathrm{C}$ systems find wide applications in catalytic hydrogenation reactions for the industrial synthesis of fine chemicals [7, 9-12]. Morphology, porous structure, and surface properties of carbonaceous materials directly affect catalyst performance (e.g., activity) and the degree of dispersion and stability of the precious metal crystallites [13-17]. For this reason, the identification and detailed characterization of carbons are a mandatory step in the optimization of the catalysts' performances. Nevertheless activated carbons are complex materials derived from natural sources and subjected to various activation processes, so that they may display important differences.

In this work we deal with the surface properties activated carbons. In this respect, infrared (IR) spectroscopy has been widely used to characterize the surface groups in coals, carbon blacks, chars, carbon films, and activated carbons [1827]. However, IR spectra of carbon materials are difficult to obtain because of problems in sample preparation, poor transmission, and uneven light scattering related to large particle size. Besides the experimental difficulties, the interpretation of IR spectra of carbons is often an additional problem, mainly because they are usually characterized by the overlap 
of many broad bands, which are difficult to be assigned unequivocally to specific molecular motions of functional groups. For this reason, only a general and qualitative identification of a few functional groups has been possible so far.

On the other hand, inelastic neutron scattering (INS) has been shown to be a useful technique complementary to IR for detailed studies on carbons or precious metal/carbon catalysts [28-32]. The incoherent scattering cross section of the hydrogen atom is more than one order of magnitude greater than those of other atoms such as carbon, oxygen, or nitrogen; hence, INS is suited to observe the vibrational spectra of hydrogenous species in carbons. Moreover, all vibrational modes are observable and band intensities are simply related to the amount of the corresponding hydrogenous species and how much they displace with respect to the equilibrium position. Hydrogen atoms are present in activated carbons (and related carbonaceous materials) mainly at the edges of the $\mathrm{sp}^{2}$ graphitic domains (which are the basic structural units) and in less extent in functional groups containing other heteroatoms (such as carboxylic groups, - $\mathrm{COOH}$, or hydroxyl groups, -OH). These species are assumed to be of practical relevance in influencing the interactions of carbon surface with the finely divided precious metal nanoparticles during catalyst preparation, as well as for the adsorption of organic reactants during catalyst operation.

Quantum chemistry methods may be employed to calculate vibrational frequencies of a large set of polyaromatic model compounds to compare with experimental IR and INS spectra $[19,28-30]$. Intensities of IR bands are calculated by evaluating the Born charges as polarization differences between the relaxed and the distorted geometries. This complicates the dependence of intensities on the vibration polarization, so that quantitative results are not easily achievable. On the contrary, INS spectra are directly proportional to the nucleus incoherent cross section and to the square of the normal mode displacements, which makes quantitative analysis easy and robust [33]. In all cases, the limiting step in the accuracy of calculation for carbonaceous material is the choice of the model, which should be big enough to be distant from a molecule and represent a heterogeneous structure but small enough to be computable in a reasonable time scale.

Here we present a detailed DFT-based vibrational analysis of hydrogenous surface species in carbons and of a few oxygen-containing functional groups, based on different structural models of increasing complexity. The theoretical results are compared to the INS spectrum of an industrially relevant activated carbon. Thanks to the quality of the experimental spectrum, characterized by well-resolved bands, and to the fine level of theory used, we succeeded in precisely assigning the experimental spectroscopic features to specific surface species.

\section{Experimental and Theoretical Methods}

2.1. DFT Calculations. Density Functional Theory (DFT) calculations have been performed with the CRYSTAL09 code $[34,35]$. DFT calculations have been performed using the B3LYP hybrid functional, corresponding to Becke's threeparameter exchange functional [36], and the Lee-Yang-Parr gradient-corrected correlation functional [37]. All electron basis sets were used for $\mathrm{C}, \mathrm{O}$, and $\mathrm{H}$.

To test the effect of different basis sets we calculated the INS spectrum of toluene using the $3-21 \mathrm{G}+* *, 6-31 \mathrm{G}+(\mathrm{d}$, p), 6-31G $++(2 d, 2 p), 6-311 G++(2 d, 2 p), 6-311 G++(3 d, 3 p)$, DZVP, and TZVP. The first three basis sets did not reproduce adequately the mode frequencies and intensities. The other entire basis sets showed the same good agreement on mode frequencies in the range $0-1300 \mathrm{~cm}^{-1}$, but the relative intensity of the modes is best represented by the TZVP calculations. For this reason, the basis set of choice was a TZVP with three sets of polarization functions [38].

All of the model compounds studied in this work have been input as molecular clusters (MOLECULE keyword) and have been first fully optimized. The correctness of this approximation, which discard effects due to interplatelets interactions, is related to the fact that we deal with activated carbons, where regular ordered domains exist only inside each single platelet at the nanometric scale, while regular stacking of several graphitic platelets is not really probable in this kind of material. Due to the fact that dispersive forces are generally weak and that there is no regular patterning of these forces that could have driven to a detectable shift in the vibrational bands, we can be confident that irregular stacking of platelets should not affect really much vibrational modes of terminal hydrogen atoms.

Following geometry optimizations, harmonic vibrational frequencies and dipole moment derivatives were calculated analytically. The condition for the SCF convergence was set to $10^{-8}$ and $10^{-10}$ hartrees during geometry optimization and frequency calculation steps, respectively. For the numerical integration of the exchange-correlation term, the XLGRID option inside the Lebedev scheme was adopted. The five truncation criteria (TOLINTEG) for the bielectronic integrals were set to 777714 . A modified Broyden scheme was adopted to accelerate convergence in the self-consistent calculations; the method was applied after four SCF iterations, with $50 \%$ of Fock/KS matrices mixing and with the Johnson parameter set to 0.001 [39].

2.2. Sample. The measured sample is an industrially relevant carbon from wood source, activated at high temperature in presence of steam. The sample (CW in the following) was provided by Chimet S.p.A. The specific surface area as determined by nitrogen adsorption measurements at $77 \mathrm{~K}$ was $1020 \mathrm{~m}^{2} \mathrm{~g}^{-1}$, and the total pore volume was $0.63 \mathrm{~mL} \mathrm{~g}^{-1}$. For INS measurements, CW was degassed until $10^{-5}$ bar for $24 \mathrm{~h}$ in order to remove any unwanted physisorbed water.

2.3. INS. Inelastic neutron scattering experiment was performed on the TOSCA spectrometer at ISIS spallation source [40]. The INS spectrum was measured with a high statistic by integrating for $1500 \mu \mathrm{A}$ of incoming proton current (proton accelerator was working at about $150 \mu \mathrm{A}$ /hour). Signals from detectors both in forward and in backward directions have been extracted and combined using Mantid software [41], without any sign of degradation of the resolution. The measured sample weighted 7.7 grams and was inserted in 

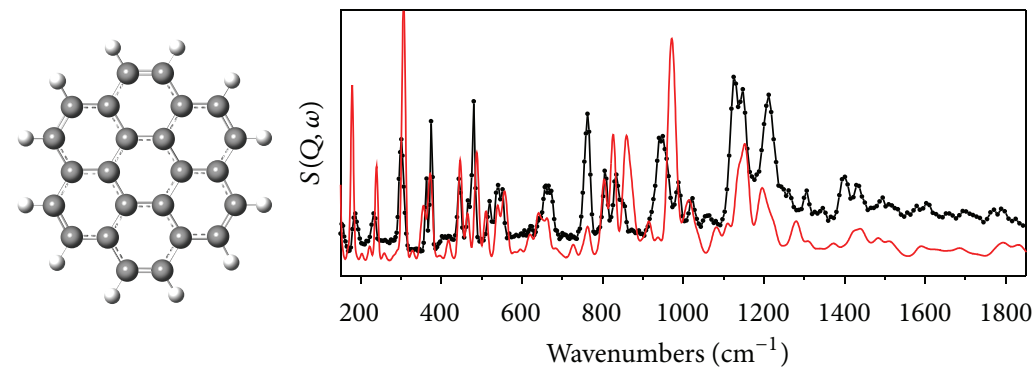

(a)
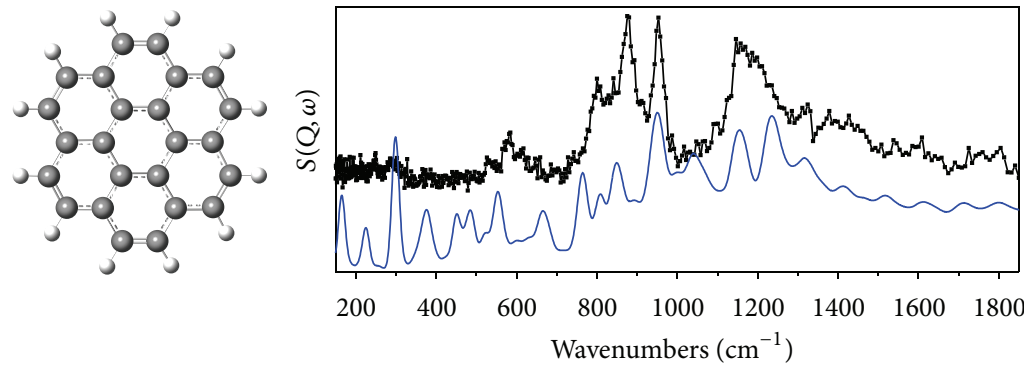

(b)

Figure 1: (a) Comparison between the experimental INS spectrum of coronene (black curve), collected by Mitchell et al. [28], and the calculated one (this work, red curve). This comparison is used to verify the level of precision of the simulations. (b) Comparison between the experimental INS spectrum of CW (dotted curve) and the calculated one (blue curve) considering isotropic phonon tails and a larger instrumental resolution to mimic structural disorder. The calculated spectrum has been vertically shifted for clarity.

a thin aluminium envelope and successively placed into inwire sealed Al cells. All the manipulations were performed inside a glove-box to prevent contamination by moisture. The sample was prepared so that it fits the beam dimension of $40 \mathrm{~mm} \times 40 \mathrm{~mm}$. Finally, the sample was inserted in a duplex CCR cryostat allowing measurements to be run at $20 \mathrm{~K}$.

The calculated inelastic neutron scattering spectra have been obtained from the output of vibrational analysis using the aClimax software [42]. For coronene, the contribution of second overtones has been included, while any effect of phonon tails has been considered. A spectrum convolution of $\Delta E / E \approx 2 \%$ has been chosen. For carbon clusters, contributions up to 10 th overtone and isotropic phonon tails have been included and a broader $\Delta E / E \approx 4 \%$ spectral convolution has been included. The experimental spectrum of coronene, used as a reference, was downloaded from TOSCA INS database $[28,43]$.

\section{Results and Discussion}

In order to validate the theoretical method, we performed a preliminary simulation of the INS spectrum of coronene, which can be seen as a connecting structure in between large aromatic molecules and small clusters acting as prototypes of carbonaceous fragments. Figure 1(a) shows the experimental INS spectrum of coronene (black curve) compared to the calculated spectrum (red curve). The spectrum is characterized by a large number of bands, most of which are well reproduced in terms of both wavenumbers position and intensity.

Figure 1(b) shows the experimental INS spectrum of CW (dotted curve). It is evident that it is characterized by a much smaller number of bands (and also broader) with respect to that of coronene. This suggests that the $\mathrm{sp}^{2}$ domains constituting $\mathrm{CW}$ are in average larger than coronene and lack the molecular character. In the INS spectrum of CW, we can distinguish three main vibrational regions: (i) $150-700 \mathrm{~cm}^{-1}$, (ii) $700-1000 \mathrm{~cm}^{-1}$, and (iii) $1100-1700 \mathrm{~cm}^{-1}$. Previous assignments ascribe the vibrational contributions in region (i) to riding modes of hydrogen on top of the $\mathrm{C}-\mathrm{C}$ aromatic vibrations $[28,29]$. In this region, a broad band with a more defined peak centred at $580 \mathrm{~cm}^{-1}$ is observed in the spectrum of CW. More attention has been accorded to modes that fall in region (ii).

It has been demonstrated that the vibrational frequencies of the $\mathrm{C}-\mathrm{H}$ deformational modes of aromatic species are dependent on the number of adjacent hydrogen atoms. According to the nomenclature proposed by Zander, for substituted benzenes the following values were reported: $860-$ $910 \mathrm{~cm}^{-1}$ for an isolated hydrogen atom (solo), $800-860 \mathrm{~cm}^{-1}$ for two adjacent hydrogen atoms (duo), and $750-770 \mathrm{~cm}^{-1}$ and $770-810 \mathrm{~cm}^{-1}$ for three adjacent hydrogen atoms (trio) $[18,29]$. In this frequency region, the spectrum of CW shows three well-defined bands at 950,880 , and $805 \mathrm{~cm}^{-1}$ and two additional weak and less evident bands around $830 \mathrm{~cm}^{-1}$ and $770 \mathrm{~cm}^{-1}$, as summarized in Table 1 . Finally region (iii) includes modes corresponding to in-plane C-H bending [29]. Here the spectrum of CW shows a broad and unresolved band centred around $1160 \mathrm{~cm}^{-1}$.

The experimental INS spectrum of CW is compared in Figure 1(b) with that calculated for coronene, which can be considered as a minimal carbonaceous fragment terminating 
TABLE 1: Frequencies values (in $\mathrm{cm}^{-1}$ ) of the main bands observed in the experimental INS spectrum of CW in the C-H out-of-plane bending region (ii) and values calculated for the two models shown in Figures 2 (a) and 2(b), with relative intensities $(\mathrm{s}=\mathrm{strong}, \mathrm{m}=\mathrm{medium}$, and $\mathrm{w}=$ weak). The assignment to the specific $\mathrm{C}-\mathrm{H}$ out-of-plane mode is indicated in the last column.

\begin{tabular}{lcccc}
\hline Exp. $\left(\mathrm{cm}^{-1}\right)$ & Coronene $\left(\mathrm{cm}^{-1}\right)$ & Model $1\left(\mathrm{~cm}^{-1}\right)$ & Model $2\left(\mathrm{~cm}^{-1}\right)$ & C-H mode \\
\hline 956 & $953 \mathrm{~s}$ & $958 \mathrm{~s}$ & $968 \mathrm{~s}$ & duo, trio, quatro: defective borders \\
882 & - & $873 \mathrm{~s}$ & $894 \mathrm{w}$ & solo: extended borders \\
820 & $850 \mathrm{~s}$ & $820 \mathrm{w}$ & - & duo, trio \\
764 & $761 \mathrm{~s}$ & - & $761 \mathrm{~m}$ & duo, trio \\
\hline
\end{tabular}
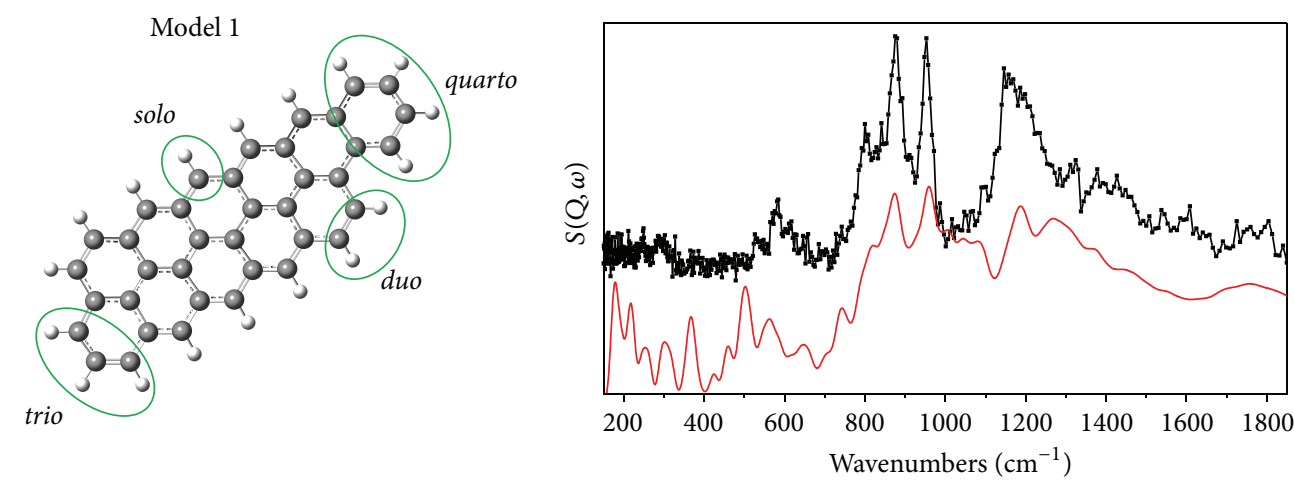

(a)
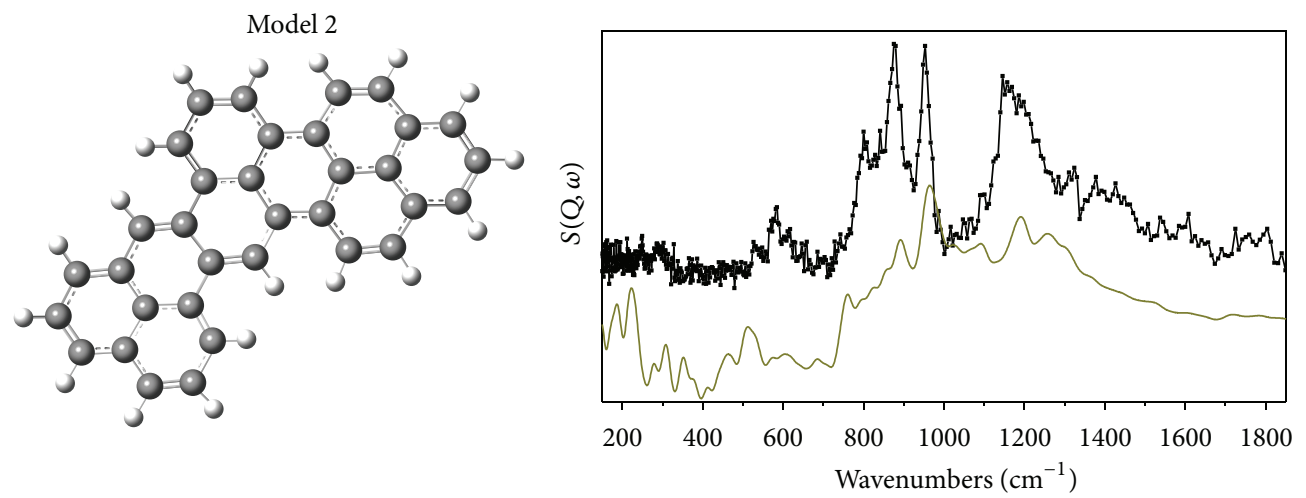

(b)

Figure 2: Two different model clusters used to represent surface C-H species present on activated carbons. Each model has a different proportion of C-H solo: duo : trio : quatro, defined as evidenced in green circles. Independently of the model, the mode at $950 \mathrm{~cm}^{-1}$ is always intense, while the modes at lower frequencies $\left(905,880,820\right.$, and $\left.760 \mathrm{~cm}^{-1}\right)$ depend on the proportion of the different species present. The calculated spectra (full curves, vertically shifted for clarity) are compared to the experimental INS spectrum of CW (dotted curve).

only with duo hydrogen species. It is evident that, also by including a broader $\Delta E / E$ spectral convolution, the coronene model is unable to reproduce the experimental spectrum because it still carries on well-defined (molecular like) modes. It is also clear that only duo hydrogen terminations are not sufficient to correctly reproduce the experimentally observed bands in the $\mathrm{C}-\mathrm{H}$ out-of-plane bending modes region.

With the aim of performing a more rigorous assignment of contributions in region (ii), we constructed two models larger and less symmetric than coronene, terminating also with solo, trio, and quatro hydrogen species in different amount. Model 1 (Figure 2(a)) contains 11 condensed aromatic rings and terminates with hydrogen species in the proportion with solo: duo: trio: quatro $=7: 2: 1: 1$; Model 2
(Figure 2(b)) is constituted by 9 condensed aromatic rings and terminates with hydrogen species in the proportion solo: duo: trio: quatro $=2: 2: 4: 0$. The calculated INS spectra corresponding to the two models are compared to the experimental spectrum of CW in Figures 2(a) and 2(b). It is clear that the two models, which are more extended and irregular than coronene, better reproduce the experimental spectrum. It is also evident that the different ratio of hydrogen species largely affects the calculated spectra. Indeed, Model 1 that includes all the possible $\mathrm{C}$ - $\mathrm{H}$ border environments is the one that represents at best the experimental spectrum.

Experimental frequencies of modes in region (ii) are summarized in Table 1, together with the frequencies calculated for coronene, Model 1 and Model 2. Coronene terminates 


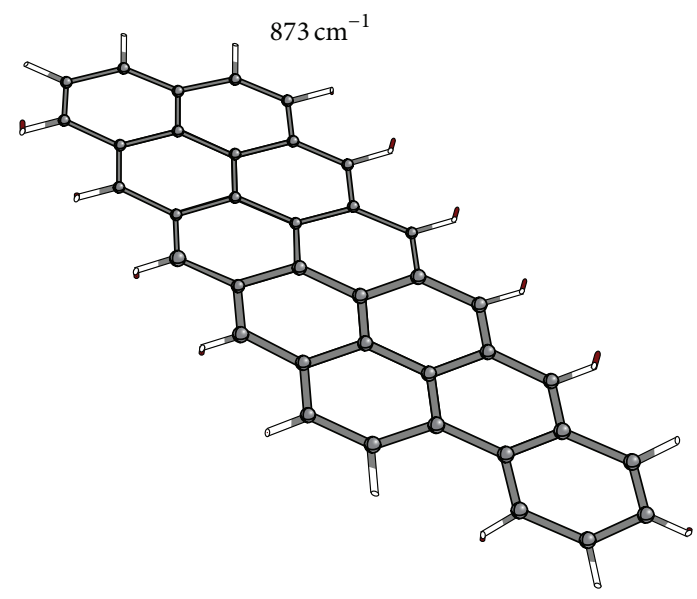

(a)

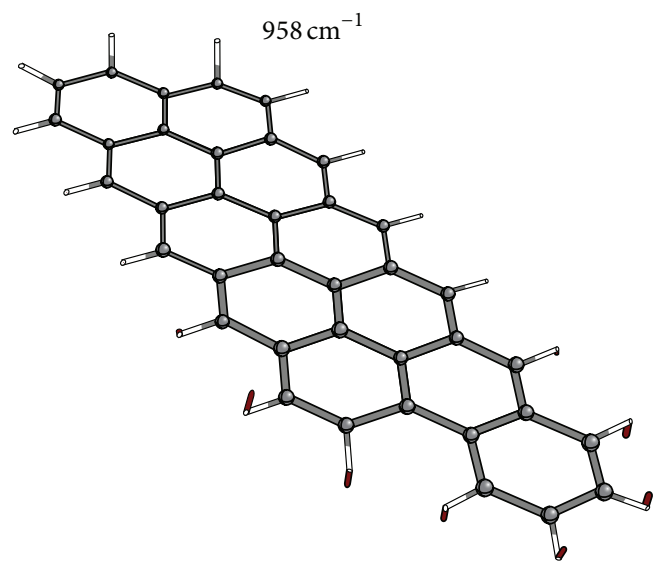

(b)

FIgURE 3: Calculated INS vibrational modes for Model 1 in region (ii). Carbon atoms are grey, hydrogen atoms white, and displacement vectors red arrows. The contribution at $873 \mathrm{~cm}^{-1}$ is clearly connected to an in-phase oscillation of solo species on well-extended borders, while the intense mode at $958 \mathrm{~cm}^{-1}$ is connected to out-of-phase modes at duo, trio, and quatro sites that characterize a defective and not extended border.

with only duo hydrogen species: hence, the calculated band at $850 \mathrm{~cm}^{-1}$ (strong) can be directly ascribed to the C-H out-ofplane bending of duo hydrogen species. Model 1 has a large majority of solo hydrogen sites; thus, the calculated band at $873 \mathrm{~cm}^{-1}$ (strong) can be ascribed to the $\mathrm{C}-\mathrm{H}$ out-of-plane bending of solo hydrogen species. Finally, for Model 2, the calculated band at $761 \mathrm{~cm}^{-1}$ is relatively high in intensity and is assigned to vibrations of trio hydrogen species. The calculated frequency values summarized in Table 1 allow us to assign the experimental bands observed in the $900-750 \mathrm{~cm}^{-1}$ region, as indicated in the last column of Table 1. Our assignment is in accordance with that proposed by Centrone et al. on the basis of infrared spectra of polyconjugated molecules [18].

The experimental INS spectrum of CW shows an additional intense band at $956 \mathrm{~cm}^{-1}$, which is correctly reproduced by all models. This band is not observed in IR spectra of carbonaceous materials [18-27]. Hence, it might be associated with a specific vibration with a symmetry forbidden in IR. Alternatively, it could be associated with the vibration of isolated $\mathrm{C}-\mathrm{H}$ species in depleted $\mathrm{H}$ zones.

In Figure 3 are reported the two most important vibrational modes contributing in region (ii) for Model 1. It is interesting to note that the vibration at $873 \mathrm{~cm}^{-1}$ is clearly connected to an in-phase oscillation of solo species on wellextended borders, whose intensity can be then directly connected to the regularity of the graphitic platelets constituting the carbon. On the contrary, the intense mode at $958 \mathrm{~cm}^{-1}$ is connected to out-of-phase modes at duo, trio, and quatro sites that characterize not extended borders or highly exposed corners and then can be connected to the defectivity of the graphitic fragments.

As a final step, we have evaluated the effect of a few oxygen-containing functional groups (namely, carboxyls and phenols) on the overall INS spectrum of an activated carbon. Indeed, there is large agreement in literature that active carbons include oxygen species to some extent $[22,24$, $27,44]$. As already mentioned, an important advantage of calculated INS spectra is that it is easy to selectively enhance the vibrations of a selected fragment by acting on the cross section and mass of the elements.

For this purpose, we constructed a simple model with two condensed aromatic rings on top of which we attached an isolated carboxyl (Figure 4(a)) or phenol (Figure 4(b)) species. Although the "carbon-like" part is not extended, our interest was in computing a model where species are connected to an aromatic ring in order not to calculate them as isolated one, as could be in principle incorrect. Calculations were performed by putting null cross section to the aromatic part and computing the contribution of oxygen-containing species attached to the aromatic carbon.

The results are shown in Figure 4(a) for the carboxyl species and in Figure 4(b) for the phenol species, compared to the experimental INS spectrum of CW. Vibrational modes involving the carboxyl group mostly fall in the $500-700 \mathrm{~cm}^{-1}$ region, where also $\mathrm{H}$ riding modes of standard $\mathrm{C}-\mathrm{H}$ terminations participate. However, it is interesting to observe that the most intense and sharp peak at $580 \mathrm{~cm}^{-1}$ fits very well with a sharp experimental peak at the same frequency, which is tentatively ascribed to a molecular-like mode of surface carboxyl groups. On the contrary, the most important calculated contribution for the phenol species is at $290 \mathrm{~cm}^{-1}$ and falls in a frequency region where the experimental spectrum shows a broad and poorly resolved peak.

\section{Conclusions}

Optimized DFT calculations on different carbon models of increasing complexity have been analyzed well in detail to be able to assign the various vibrational modes to specific surface species in activated carbons with confidence. Calculations 

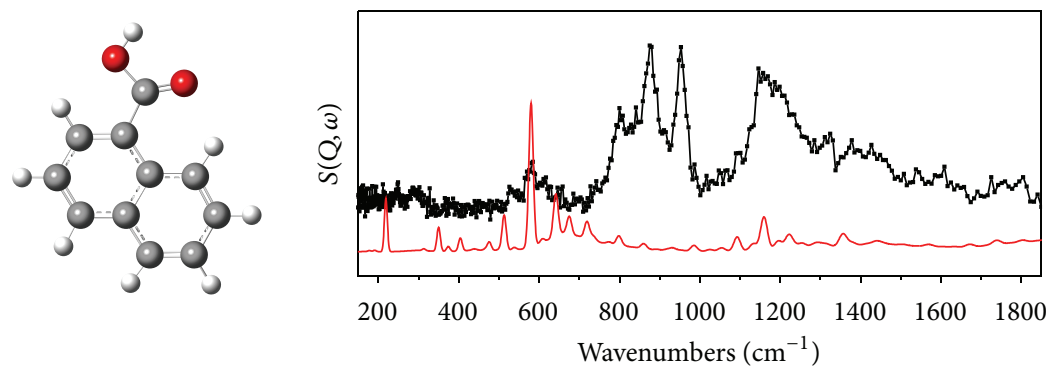

(a)
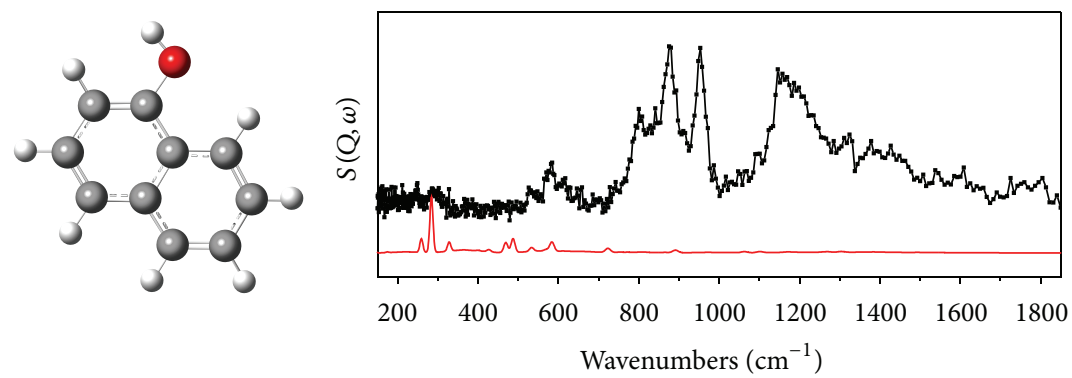

(b)

FIGURE 4: Simple models of a carbon fragment with an oxygen-containing functional group: (a) carboxyl and (b) phenol. The computed INS spectrum is obtained by putting the cross section of all the $\mathrm{C}$ and $\mathrm{H}$ atoms belonging to the aromatic rings artificially to 0 barns. The resulting spectra highlight the contribution of the selected species attached to the carbon cluster only. Calculated spectra (red curves) are compared to the experimental INS spectrum of CW (dotted curve).

have been compared to the INS spectrum of an industrially relevant activated carbon. Since INS technique is highly sensitive to the movement of hydrogenous species, it is intrinsically selective towards surface species present on these samples.

Both our calculations and experimental spectrum show better resolved features than in any other work present in literature. The combination of different models, containing all possible $\mathrm{C}-\mathrm{H}$ terminations (solo, duo, trio, and quarto), was necessary to unambiguously attribute all the observed spectral features. In particular, we were able to assign with a high level of confidence the vibrational modes in the 700$1000 \mathrm{~cm}^{-1}$ region (out-of-plane $\mathrm{C}-\mathrm{H}$ bending modes) as due to specific contributions of solo, duo, and trio species. According to our calculations, the mode at $956 \mathrm{~cm}^{-1}$, unattributed so far, represents a C-H out-of-plane bending vibration associated with hydrogen species at defective borders. Definitely, a model including both extended regular borders and reduced defective borders is necessary to correctly reproduce both the position and the relative intensity of the vibrational modes in the $700-1000 \mathrm{~cm}^{-1}$ region.

Finally calculation on a minimal model containing $\mathrm{COOH}$ species allowed us to assign a feature in the region $150-700 \mathrm{~cm}^{-1}$, where also $\mathrm{H}$ riding modes contribute to the experimental spectrum, to a specific involvement of carboxyl species. Nevertheless, the simulation of fragments including heteroatoms is more challenging due to the fact that their contribution to the spectra is weak and falls in a less resolved spectral region.

This work shows that, with the present quality of DFT calculations and of experimental INS data, it is possible to characterize well in detail the surface chemistry of complex materials as activated carbons.

\section{Conflict of Interests}

The authors declare that there is no conflict of interests regarding the publication of this paper.

\section{Acknowledgment}

Aram L. Bugaev and Carlo Lamberti acknowledge the MegaGrant of the Russian Federation Government to support scientific research at the Southern Federal University, no. 14.Y26.31.0001.

\section{References}

[1] X. Yu and S. Ye, "Recent advances in activity and durability enhancement of $\mathrm{Pt} / \mathrm{C}$ catalytic cathode in PEMFC: part I. Physico-chemical and electronic interaction between $\mathrm{Pt}$ and carbon support, and activity enhancement of Pt/C catalyst," Journal of Power Sources, vol. 172, no. 1, pp. 133-144, 2007.

[2] Z. L. Liu, X. Y. Ling, X. D. Su, and J. Y. Lee, "Carbon-supported $\mathrm{Pt}$ and PtRu nanoparticles as catalysts for a direct methanol fuel cell," Journal of Physical Chemistry B, vol. 108, no. 24, pp. 82348240, 2004.

[3] E. Antolini, "Formation of carbon-supported PtM alloys for low temperature fuel cells: a review," Materials Chemistry and Physics, vol. 78, no. 3, pp. 563-573, 2003.

[4] U. A. Paulus, A. Wokaun, G. G. Scherer et al., "Oxygen reduction on carbon-supported Pt-Ni and Pt-Co alloy catalysts," 
Journal of Physical Chemistry B, vol. 106, no. 16, pp. 4181-4191, 2002.

[5] E. Auer, A. Freund, J. Pietsch, and T. Tacke, "Carbons as supports for industrial precious metal catalysts," Applied Catalysis A: General, vol. 173, no. 2, pp. 259-271, 1998.

[6] T. Wigmans, "Industrial aspects of production and use of activated carbons," Carbon, vol. 27, no. 1, pp. 13-22, 1989.

[7] R. Pellegrini, G. Agostini, E. Groppo, A. Piovano, G. Leofanti, and C. Lamberti, " 0.5 wt.\% $\mathrm{Pd} / \mathrm{C}$ catalyst for purification of terephthalic acid: irreversible deactivation in industrial plants," Journal of Catalysis, vol. 280, no. 2, pp. 150-160, 2011.

[8] E. Antolini, "Palladium in fuel cell catalysis," Energy \& Environmental Science, vol. 2, no. 9, pp. 915-931, 2009.

[9] E. Groppo, G. Agostini, A. Piovano et al., "Effect of reduction in liquid phase on the properties and the catalytic activity of $\mathrm{Pd} / \mathrm{Al}_{2} \mathrm{O}_{3}$ catalysts," Journal of Catalysis, vol. 287, pp. 44-54, 2012.

[10] G. Agostini, C. Lamberti, R. Pellegrini et al., "Effect of prereduction on the properties and the catalytic activity of $\mathrm{Pd} /$ carbon catalysts: a comparison with $\mathrm{Pd} / \mathrm{Al}_{2} \mathrm{O}_{3}$," ACS Catalysis, vol. 4, no. 1, pp. 187-194, 2014.

[11] C. Bock, C. Paquet, M. Couillard, G. A. Botton, and B. R. MacDougall, "Size-selected synthesis of PtRu nano-catalysts: reaction and size control mechanism," Journal of the American Chemical Society, vol. 126, no. 25, pp. 8028-8037, 2004.

[12] C. L. Bianchi, S. Biella, A. Gervasini, L. Prati, and M. Rossi, "Gold on carbon: influence of support properties on catalyst activity in liquid-phase oxidation," Catalysis Letters, vol. 85, no. 1-2, pp. 91-96, 2003.

[13] E. Groppo, S. Bertarione, F. Rotunno et al., "Role of the support in determining the vibrational properties of carbonyls formed on $\mathrm{Pd}$ supported on $\mathrm{SiO}_{2}-\mathrm{Al}_{2} \mathrm{O}_{3}, \mathrm{Al}_{2} \mathrm{O}_{3}$, and MgO," Journal of Physical Chemistry C, vol. 111, no. 19, pp. 7021-7028, 2007.

[14] R. Pellegrini, G. Leofanti, G. Agostini, E. Groppo, M. Rivallan, and C. Lamberti, "Pd-supported catalysts: evolution of support porous texture along Pd deposition and alkali-metal doping," Langmuir, vol. 25, no. 11, pp. 6476-6485, 2009.

[15] G. Agostini, R. Pellegrini, G. Leofanti et al., "Determination of the particle size, available surface area, and nature of exposed sites for silica-alumina-supported Pd nanoparticles: a multitechnical approach," The Journal of Physical Chemistry C, vol. 113, no. 24, pp. 10485-10492, 2009.

[16] G. Agostini, E. Groppo, A. Piovano, R. Pellegrini, G. Leofanti, and C. Lamberti, "Preparation of supported Pd catalysts: from the Pd precursor solution to the deposited $\mathrm{Pd}^{2+}$ phase," Langmuir, vol. 26, no. 13, pp. 11204-11211, 2010.

[17] F. Rodríguez-Reinoso, "The role of carbon materials in heterogeneous catalysis," Carbon, vol. 36, no. 3, pp. 159-175, 1998.

[18] A. Centrone, L. Brambilla, T. Renouard et al., "Structure of new carbonaceous materials: the role of vibrational spectroscopy," Carbon, vol. 43, no. 8, pp. 1593-1609, 2005.

[19] E. Fuente, J. A. Menéndez, M. A. Díez, D. Suárez, and M. A. Montes-Morán, "Infrared spectroscopy of carbon materials: a Quantum Chemical Study of Model Compounds," The Journal of Physical Chemistry B, vol. 107, no. 26, pp. 6350-6359, 2003.

[20] C. Moreno-Castilla, M. V. López-Ramón, and F. CarrascoMarín, "Changes in surface chemistry of activated carbons by wet oxidation," Carbon, vol. 38, no. 14, pp. 1995-2001, 2000.

[21] J. L. Figueiredo, M. F. R. Pereira, M. M. A. Freitas, and J. J. M. Órfão, "Modification of the surface chemistry of activated carbons," Carbon, vol. 37, no. 9, pp. 1379-1389, 1999.
[22] M. J. Iglesias, G. de la Puente, E. Fuente, and J. J. Pis, "Compositional and structural changes during aerial oxidation of coal and their relations with technological properties," Vibrational Spectroscopy, vol. 17, no. 1-3, pp. 41-52, 1998.

[23] A. Dandekar, R. T. K. Baker, and M. A. Vannice, "Characterization of activated carbon, graphitized carbon fibers and synthetic diamond powder using TPD and DRIFTS," Carbon, vol. 36, no. 12, pp. 1821-1831, 1998.

[24] S. Biniak, G. Szymański, J. Siedlewski, and A. Światkoski, “The characterization of activated carbons with oxygen and nitrogen surface groups," Carbon, vol. 35, no. 12, pp. 1799-1810, 1997.

[25] J. K. Walters, R. J. Newport, S. F. Parker, and W. S. Howells, "A spectroscopic study of the structure of amorphous hydrogenated carbon," Journal of Physics: Condensed Matter, vol. 7, no. 50, 1995.

[26] F. Rositani, P. L. Antonucci, M. Minutoli, N. Giordano, and A. Villari, "Infrared analysis of carbon blacks," Carbon, vol. 25, no. 3, pp. 325-332, 1987.

[27] M. Starsinic, R. L. Taylor, P. L. Walker Jr., and P. C. Painter, "FTIR studies of Saran chars," Carbon, vol. 21, no. 1, pp. 69-74, 1983.

[28] P. C. H. Mitchell, A. J. Ramirez-Cuesta, S. F. Parker, and J. Tomkinson, "Inelastic neutron scattering in spectroscopic studies of hydrogen on carbon-supported catalysts-experimental spectra and computed spectra of model systems," Journal of Molecular Structure, vol. 651-653, pp. 781-785, 2003.

[29] P. W. Albers, J. Pietsch, J. Krauter, and S. F. Parker, "Investigations of activated carbon catalyst supports from different natural sources," Physical Chemistry Chemical Physics, vol. 5, no. 9, pp. 1941-1949, 2003.

[30] P. W. Albers and S. F. Parker, "Inelastic incoherent neutron scattering in catalysis research," Advances in Catalysis, vol. 51, pp. 99-132, 2007.

[31] P. J. R. Honeybone, R. J. Newport, J. K. Walters, W. S. Howells, and J. Tomkinson, "Structural properties of amorphous hydrogenated carbon. II. An inelastic neutron-scattering study," Physical Review B, vol. 50, no. 2, pp. 839-845, 1994.

[32] F. Fillaux, R. Papoular, A. Lautie, and J. Tomkinson, "Inelastic neutron-scattering study of the proton dynamics in carbons and coals," Carbon, vol. 32, no. 7, pp. 1325-1331, 1994.

[33] P. C. H. Mitchell, F. S. Parker, A. J. Ramirez-Cuesta, and J. Tomkinson, Vibrational Spectroscopy with Neutrons, World Scientific, London, UK, 2005.

[34] R. Dovesi, R. Orlando, B. Civalleri, C. Roetti, V. R. Saunders, and C. M. Zicovich-Wilson, "CRYSTAL: a computational tool for the ab initio study of the electronic properties of crystals," Zeitschrift fur Kristallographie, vol. 220, no. 5-6, pp. 571-573, 2005.

[35] R. Dovesi, V. R. Saunders, C. Roetti et al., CRYSTAL09 User's Manual, University of Torino, Torino, Italy, 2009.

[36] A. D. Becke, "Density-functional thermochemistry. III. The role of exact exchange," The Journal of Chemical Physics, vol. 98, no. 7, pp. 5648-5652, 1993.

[37] C. T. Lee, W. T. Yang, and R. G. Parr, "Development of the Colle-Salvetti correlation-energy formula into a functional of the electron density," Physical Review B, vol. 37, no. 2, pp. 785$789,1988$.

[38] M. F. Peintinger, D. V. Oliveira, and T. Bredow, "Consistent Gaussian basis sets of triple-zeta valence with polarization quality for solid-state calculations," Journal of Computational Chemistry, vol. 34, no. 6, pp. 451-459, 2013. 
[39] D. D. Johnson, “Modified Broyden's method for accelerating convergence in self-consistent calculations," Physical Review B, vol. 38, no. 18, pp. 12807-12813, 1988.

[40] D. Colognesi, M. Celli, F. Cilloco et al., "TOSCA neutron spectrometer: the final configuration," Applied Physics A: Materials Science and Processing, vol. 74, no. I, pp. S64-S66, 2002.

[41] O. Arnold, J. C. Bilheux, J. M. Borreguero et al., "Mantid-data analysis and visualization package for neutron scattering and $\mu$ SR experiments," Nuclear Instruments and Methods in Physics Research Section A: Accelerators, Spectrometers, Detectors and Associated Equipment, vol. 764, pp. 156-166, 2014.

[42] A. J. Ramirez-Cuesta, "aCLIMAX 4.0.1, the new version of the software for analyzing and interpreting INS spectra," Computer Physics Communications, vol. 157, no. 3, pp. 226-238, 2004.

[43] S. Parker, INS database, 2015, http://wwwisis2.isis.rl.ac.uk/INSdatabase/Theindex.asp.

[44] C. Ishizaki and I. Marti, "Surface oxide structures on a commercial activated carbon," Carbon, vol. 19, no. 6, pp. 409-412, 1981. 

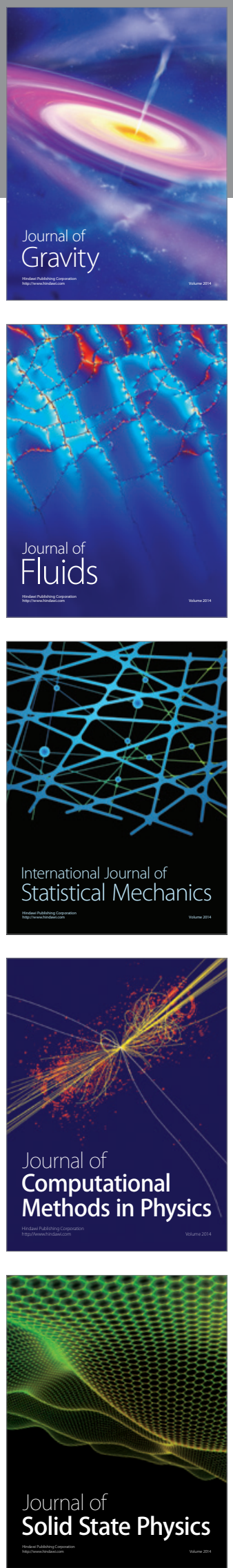

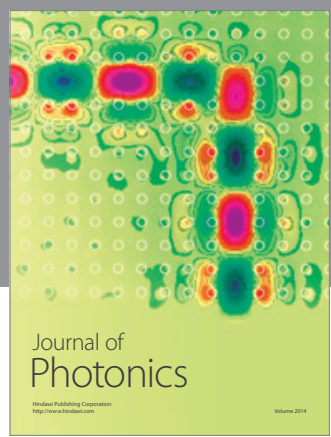

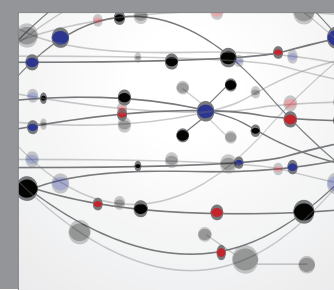

The Scientific World Journal

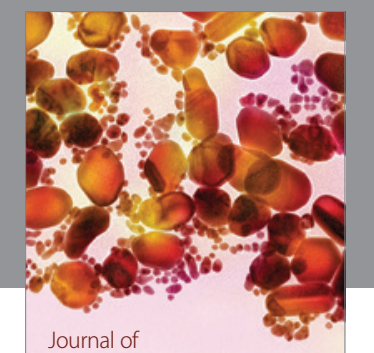

Soft Matter
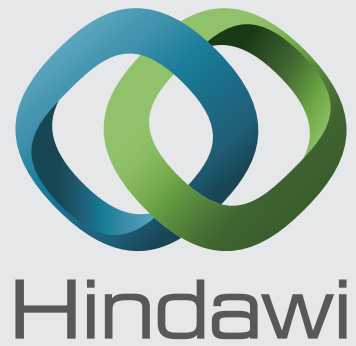

Submit your manuscripts at

http://www.hindawi.com
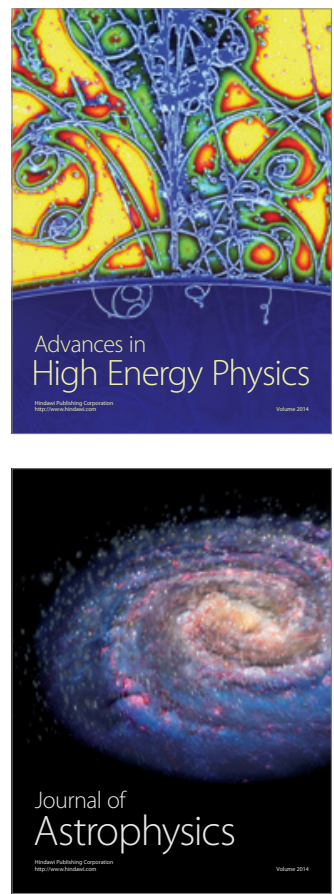
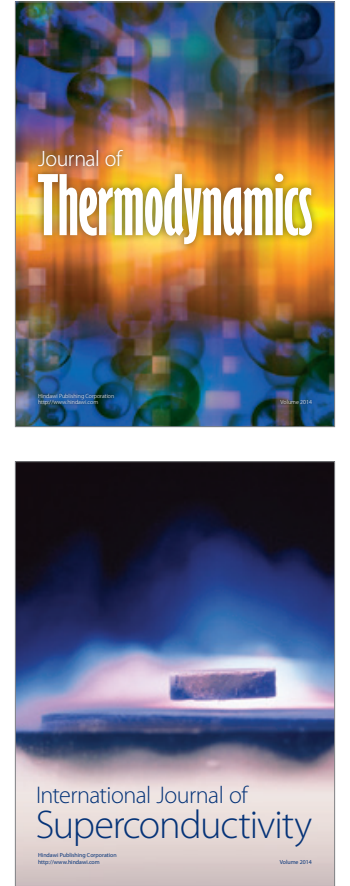
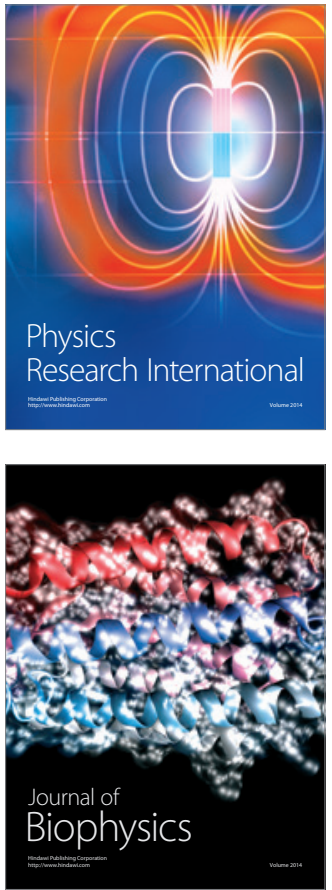
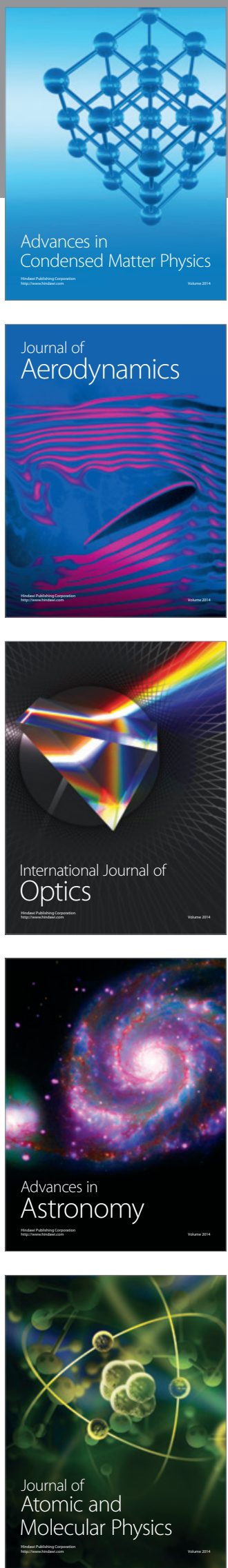